\title{
Economic profit estimation of tranmission system using novel contingency ranking with markov modelling
}

\author{
E. Sreeshobha, P.V.N. Prasad \\ Department of Electrical Engineering, University College of Engineering, Osmania University, India
}

\begin{tabular}{l} 
Article Info \\
\hline Article history: \\
Received Aug 20, 2019 \\
Revised Oct 22, 2019 \\
Accepted Nov 6, 2019 \\
\hline
\end{tabular}

\section{Keywords:}

Contingency ranking

Economic revenue

FACTS

Markov model

Transmission system

\begin{abstract}
Technique to evaluate probability of occurrence of selected contingencies of 6 Bus Roy Billinton Test System (RBTS) and IEEE 9 Bus system by Markov modelling is presented in this paper. Obtained probabilities for selected contingencies are validated by comparing with binomial distribution based probabilities. Load flow analysis and performance index based contingency ranking of total elements of 6 bus RBTS and IEEE 9 Bus systems is simulated by Power System Simulation for Engineers (PSSE) software. Novel reliability evaluation technique which unify contingency ranking with Markov modeling is proposed for RBTS and extended to IEEE 9 Bus system. Accuracy, completeness and simple to implement are salient features of proposed novel reliability evaluation method. Reliability of RBTS and IEEE 9 Bus systems can be improved by incorporating Flexible Alternating Current Transmission Systems (FACTS) device. Improvement in the reliability and economic revenue of RBTS and IEEE 9 Bus systems due to Unified Power Flow Controller (UPFC) incorporation is evaluated.
\end{abstract}

Copyright $(\odot) 2020$ Institute of Advanced Engineering and Science. All rights reserved.

\section{Corresponding Author:}

E. Sreeshobha,

Department of Electrical Engineering,

University College of Engineering,

Osmania University, Hyderabad, Telangana, India.

Email: shobhasree555@gmail.com

\section{INTRODUCTION}

System with higher operational efficiency along with economical benefit are more effective. Establishment of such systems is the need of the day [1]. Operating condition of transmission system significantly effects the composite power system operation. Physical property of merterial, environment to which conductor is exposed, the number of years a line is in service and thermal \& electrical loading at which transmission line is operating will influence the failure of transmission line. Contingencies due to these causes will drag the composite power system into unreliable operation [2]. Economic and environmental factors introducing renewable energy sources and lot of automation into the existing electrical power system [3]. Reliability of such hybrid electrical power systems, improved by Dynamic Thermal Rating (DTR) system [4-6]. To evaluate and comprehend the improvement in the reliability of the composite power system it is essential to have clarity of basic electrical power system reliability. Then only it is possible to asses the degree of improvement in the reliability. A complete systematic method of reliability evaluation of basic composite power system is presented clearly in the present paper. Contingency analysis of composite power system deals with operational aspects such as fault analysis, power carrying capability of transmission systems [7]. Examination of composite power system operational aspects, based on contingency ranking [8-9] will present partial assessment of the system. Contingency ranking cum reliability evaluation based analysis results in holistic system analysis. Very less work has been presented in the literature on contingency ranking based reliability evaluation of transmission system. System reliability is evaluated by screening severe contingencies based on Probability Performance Index (PPI) [10]. But moderately severe and less 
severe outages do effect the system operation and contribute to the unreliable operation of the system. Hence negation of moderately and less severe contingencies will result incomplete analysis and inaccurate indices of the system. Novel method, which combine contingency ranking with Markov model for reliability evaluation, including severe, moderately severe and less severe contingencies proposed in this paper. Thus obtained results, load point and system indices [11] are more accurate reliability indices of the system. Contingency constrain related to generation and evaluation of Loss of Load Expected (LOLE) is presented [12], but the proposed approach analysis transmission contingencies along with generation and evaluates complete load point and system indices.

FACTS devices play critical role in improving the system performance by reducing the transmission losses [13-16]. System contingency states which will fail to feed the load are strengthened and made capable of feeding the load due to the incorporation of UPFC. Power transported through transmission system and supplied to the load increases, thus establish more reliable system. Load demand increases day by day and it is unpredictable to assess peak load occurrences certainly. General practice to meet this scenario is installation of huge generation capacity than the expected regular normal load. Losses corresponding to excessive generation capacity when system is operating at light loads will lead to unreliable operation of the system.

Investment corresponding to excessive capacity is another economical drawback, Due to light loads operating conditions, system will encounter over voltages problems [17-18]. UPFC will address over voltage problem by establishing voltage regulation thus resulting in reliable composite power system. Along with power consumed, distribution /consumer/ loads are charged even for the power transportation losses [19]. By reducing the transmission system losses, consumer will be supplied by higher amount of power for the same bill. Supplementary power available for the load will generate the additional income to the transmission system [20]. This approach of reducing the losses by incorporation of UPFC, more economical system can be established for the consumer. Higher reliable system with economical profit is the best system which is of first choice of every consumer.

\section{CONTINGENCY RANKING WITH MARKOV MODELLING}

Newton Raphson (N-R) load flow [21] simulated on RBTS and IEEE 9 Bus systems for base case in Power System Simulation for Engineers (PSSE) software [22]. Configuration of RBTS [23-25] is shown in Figure 1 and Table 1. Figure 2 and Table 2 present the configuration of IEEE 9 Bus system. By creating each element outage based on the corresponding magnitudes of active power flows through transmission lines, contingencies are ranked in the descending order. Performance index (PI) will indicate percentage of overloading of the transmission lines. Based on PI value beyond (N-1) and (N-1)-1 contingencies, system control schemes will come into the operation and restore the system to safe operating conditions. Thus N-1 and (N-1)-1 contingencies are selected and corresponding power available to the load are listed out in Table 4 and Table 5.

Peak load of 237 MW for RBTS and 230 MW for IEEE 9 Bus system are considered for load flow. Binomial distribution is one of the standard distributions which has its application in reliability evaluation. Probability of occurrence of operating state of an element is availability A and the probability of occurrence of failure state of an element is unavailability $U$ then the availability of each element is obtained by $\mathrm{nC}_{\mathrm{r}} \mathrm{A}^{(\mathrm{n}-}$ ${ }^{\mathrm{r})} \mathrm{U}^{\mathrm{r}}$ where $\mathrm{n}$ is the total number of components $\mathrm{r}$ is outage components.

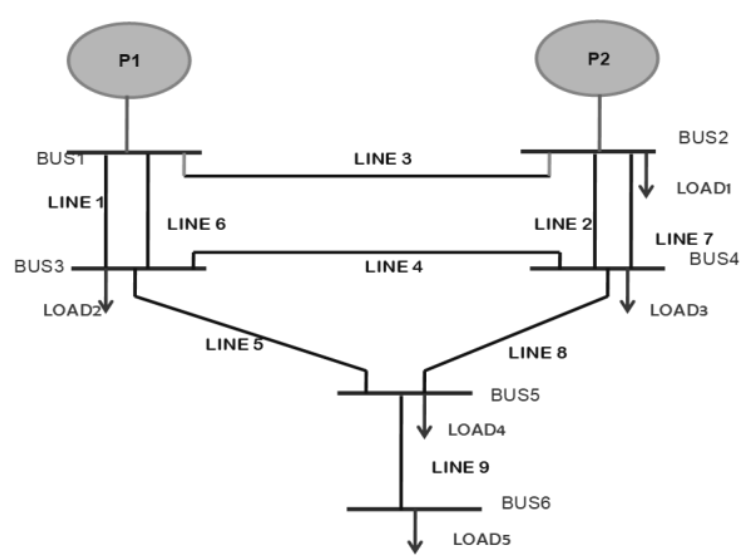

Figure 1. Schematic diagram of RBTS 6 bus system 
Table 1. RBTS Configuration

\begin{tabular}{ccccc}
\hline $\begin{array}{c}\text { No. of } \\
\text { Generators }\end{array}$ & $\begin{array}{c}\text { Capacity } \\
\text { ( MW) }\end{array}$ & $\begin{array}{c}\text { Total Capacity } \\
\text { (MW) }\end{array}$ & $\begin{array}{c}\text { Failure Rate } \lambda_{\mathrm{G}} \\
\text { (failures/year) }\end{array}$ & $\begin{array}{c}\text { Repair Rate } \mu_{\mathrm{G}} \\
\text { (repairs/year) }\end{array}$ \\
\hline 1 & 10 & 10 & 4 & 196 \\
1 & 20 & 20 & 5 & 195 \\
2 & 40 & 80 & 6 & 194 \\
2 & 5 & 10 & 2 & 198 \\
4 & 20 & 80 & 2.4 & 157.6 \\
1 & 40 & 40 & 3 & 147 \\
Transmission & From & To & Failure rate & Repair rate \\
lines & Bus & Bus & $\lambda_{\mathrm{L}}$ (failures/year) & $\mu_{\mathrm{L}}$ (repairs/ Year) \\
1 & 1 & 3 & 1.5 & 876 \\
2 & 2 & 4 & 5 & 876 \\
3 & 1 & 2 & 4 & 876 \\
4 & 3 & 4 & 1 & 876 \\
5 & 3 & 5 & 1 & 876 \\
6 & 1 & 3 & 1.5 & 876 \\
7 & 2 & 4 & 5 & 876 \\
8 & 4 & 5 & 1 & 876 \\
9 & 5 & 6 & 1 & 876 \\
\hline
\end{tabular}

Table 2. IEEE 9 Configuration

\begin{tabular}{ccccc}
\hline $\begin{array}{c}\text { No. of } \\
\text { Generators }\end{array}$ & $\begin{array}{c}\text { Capacity } \\
(\mathrm{MW})\end{array}$ & $\begin{array}{c}\text { Total Capacity } \\
(\mathrm{MW})\end{array}$ & $\begin{array}{c}\text { Failure rate } \\
\lambda_{\mathrm{G}} \text { (failures/year) }\end{array}$ & $\begin{array}{c}\text { Repair rate } \\
\mu_{\mathrm{G}} \text { (repairs/year) }\end{array}$ \\
\hline 1 & 250 & 250 & 1.1 & 73 \\
1 & 300 & 300 & 1.1 & 73 \\
1 & 270 & 270 & 0.5 & 100 \\
Transmission & From & To & Failure rate & Repair rate \\
lines & Bus & Bus & $\lambda_{\mathrm{L}}$ (failures/ year) & $\mu_{\mathrm{L}}$ (repairs/ year) \\
1 & 4 & 5 & 5 & 1095 \\
2 & 4 & 6 & 3 & 876 \\
3 & 5 & 7 & 5 & 1095 \\
4 & 6 & 9 & 3 & 876 \\
5 & 7 & 8 & 4 & 1095 \\
6 & 8 & 9 & 4 & 1095 \\
\hline
\end{tabular}

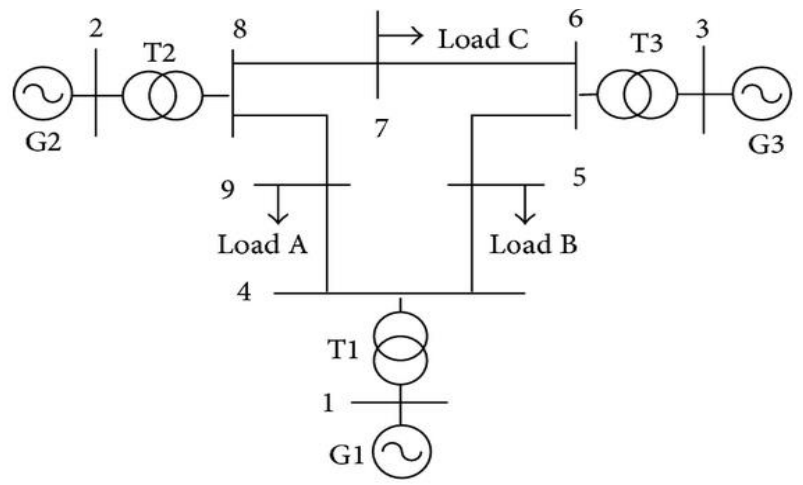

Figure 2. IEEE 9 bus system

Markov modelling is the best method out of all analytical techniques to evaluate the reliability of the system with stochastic behaviour. Application of Markov Modelling to RBTS and IEEE 9 Bus systems enable more accurate indices evaluation. Developed Markov state space models of IEEE 9 Bus system is presented in Figure 3. Stochastic transmission probability matrix is derived from limiting state equations. By solving limiting state equations the primary reliability index i.e probability of occurrence of selected contingencies is obtained. Based on this primary index remaining load point and system indices are evaluated. Probability of occurrence of contingencies obtained by Markov model are validated by comparing with binomial distribution probabilities and tabulated in Table 3. Negligible error between binomial distribution probabilities and Markov model probabilities indicate the correctness of developed Markov models. 


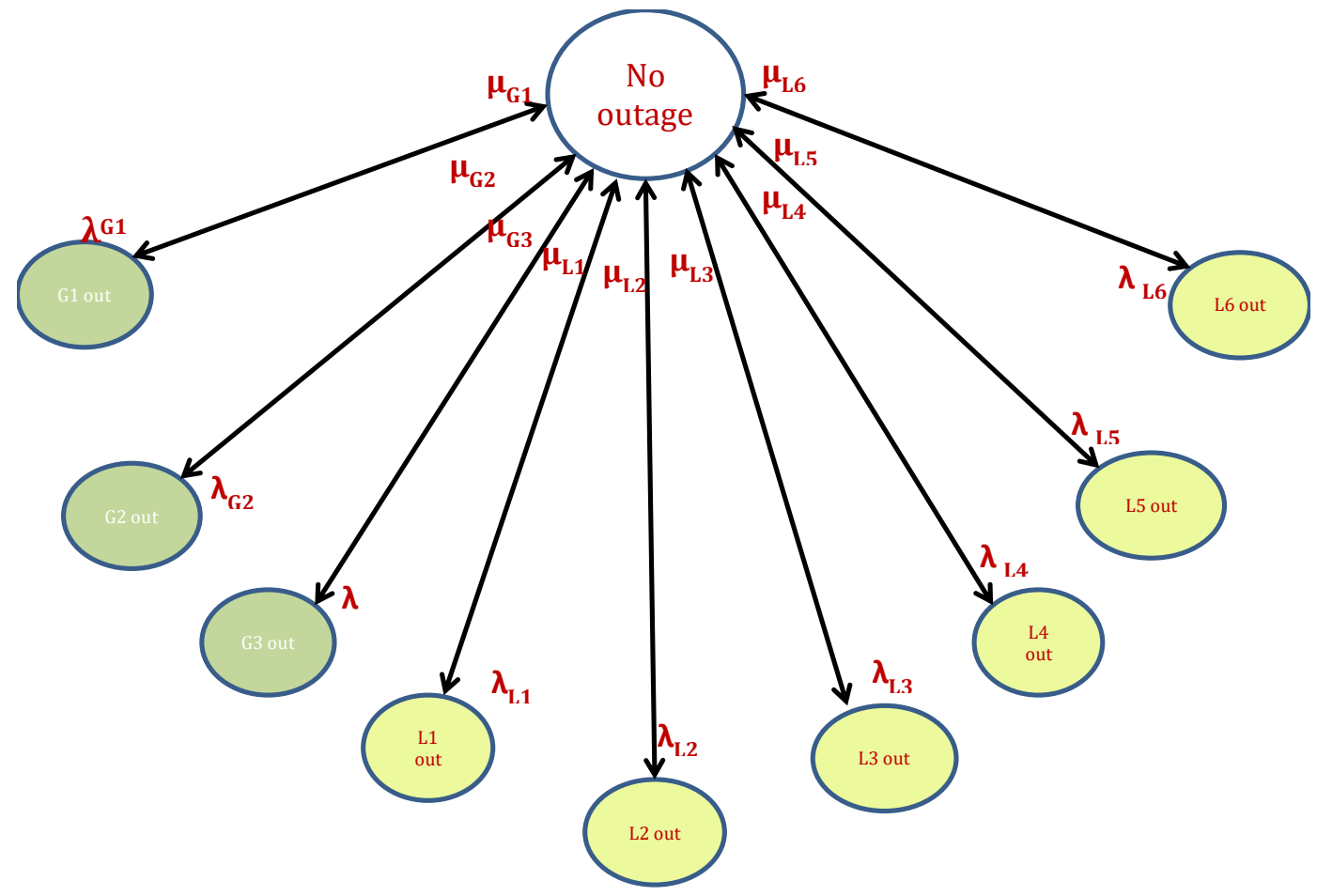

Figure 3. State space diagram of IEEE 9 bus system

Table 3. Comparison of Contingency Occurrence Probability by Binomial Distribution and Markov Model Methods

\begin{tabular}{|c|c|c|c|}
\hline S.No & Contingencies & Binomial Distribution Probabilityof Occurrence & Markov Model Probability of Occurrence \\
\hline 1 & No outages & 0.943516341 & 0.944800362 \\
\hline 2 & L3 & 0.004308294 & 0.004314157 \\
\hline 3 & L5 & 0.003446635 & 0.004314157 \\
\hline 4 & L2 & 0.00323122 & 0.003235618 \\
\hline 5 & L4 & 0.00323122 & 0.003235618 \\
\hline 6 & L6 & 0.003446635 & 0.003451326 \\
\hline 7 & L1 & 0.004308294 & 0.004314157 \\
\hline 8 & $\mathrm{G} 2$ & 0.01421737 & 0.014236718 \\
\hline 9 & G3 & 0.004717582 & 0.004724002 \\
\hline 10 & G1 & 0.01421737 & 0.014236718 \\
\hline 11 & G1 L3 & $6.49195 \mathrm{E}-05$ & $6.14194 \mathrm{E}-05$ \\
\hline 12 & G1 L5 & $5.19356 \mathrm{E}-05$ & $4.91355 \mathrm{E}-05$ \\
\hline 13 & G1 L2 & 4.86896E-05 & $4.60646 \mathrm{E}-05$ \\
\hline 14 & G2 L3 & 6.49195E-05 & 6.14194E-05 \\
\hline 15 & G2 L5 & $5.19356 \mathrm{E}-05$ & $4.91355 \mathrm{E}-05$ \\
\hline 16 & $\mathrm{G} 2 \mathrm{~L} 2$ & $4.86896 \mathrm{E}-05$ & $4.60646 \mathrm{E}-05$ \\
\hline 17 & G3 L3 & $2.15415 \mathrm{E}-05$ & $2.03801 \mathrm{E}-05$ \\
\hline 18 & G3 L5 & $1.72332 \mathrm{E}-05$ & $1.63041 \mathrm{E}-05$ \\
\hline 19 & G3 L2 & $1.61561 \mathrm{E}-05$ & $1.52851 \mathrm{E}-05$ \\
\hline 20 & G1 G2 L1 & $9.78239 \mathrm{E}-07$ & $8.74411 \mathrm{E}-07$ \\
\hline 21 & G2 L1 & 6.49195E-05 & 6.14194E-05 \\
\hline 22 & G2 G3 L1 & $3.24597 \mathrm{E}-07$ & $2.90146 \mathrm{E}-07$ \\
\hline 23 & G2 G3 L2 & $2.43448 \mathrm{E}-07$ & $2.17609 \mathrm{E}-07$ \\
\hline 24 & L1 L3 & $1.96726 \mathrm{E}-05$ & $1.86119 \mathrm{E}-05$ \\
\hline
\end{tabular}

\section{ECONOMIC PROFIT DUE TO UPFC INCORPORATION}

Load flow is simulated for selected contingencies at $237 \mathrm{MW}$ of peak for RBTS. Power available to the load is less than the demand for 8 contingency states and is indicated by $P_{k j}=1$ in Table 4 , where $P_{k j}$ is the probability of system failing to feed the load at $\mathrm{k}^{\text {th }}$ bus for $\mathrm{j}^{\text {th }}$ contingency. Due to the incorporation of UPFC power carrying capability of transmission system improves, system fails to meet the demand only in 2 contingency states instead of 8 states. Obtained reliability indices with the incorporation of UPFC indicate improvement in the system reliability. 
Peak load of IEEE 9 Bus system is $230 \mathrm{MW}$ and 17 contingencies were driving the system to failure mode of operation. UPFC incorporation resulted in reducing this to 11 states. Composite power system failure states with and without UPFC incorporation are presented in Table 5.

Incorporation of UPFC improves the power delivered to the load. Additional power delivered to the load will generate economy to the Transmission system. Transmission charges for FY 2018-2019 are 73.1243 Rs / kW / Month [26]. Without investing on erection of extra transmission lines, additional revenue is generated by incorporation of UPFC. Incorporation of UPFC is a smart solution than erection of additional transmission lines which involves environmental board clearances and right of way etc.

Table 4. RBTS-Power Available to the Load for Contingencies with and without UPFC

\begin{tabular}{|c|c|c|c|c|c|}
\hline \multirow[t]{2}{*}{ S.No } & \multirow[t]{2}{*}{ Contingencies } & \multicolumn{2}{|c|}{ Without UPFC (MW) } & \multicolumn{2}{|c|}{ With UPFC (MW) } \\
\hline & & Power available to Load & $P_{k j}$ & Power available to Load & $P_{k j}$ \\
\hline 1 & base case & 237 & 0 & 237 & 0 \\
\hline 2 & G1G1 & 237 & 0 & 237 & 0 \\
\hline 3 & $\mathrm{G} 2 \mathrm{G} 2$ & 237 & 0 & 237 & 0 \\
\hline 4 & L1 & 237 & 0 & 237 & 0 \\
\hline 5 & L2 & 237 & 0 & 237 & 0 \\
\hline 6 & L3 & 237 & 0 & 237 & 0 \\
\hline 7 & L4 & 237 & 0 & 237 & 0 \\
\hline 8 & L5 & 237 & 0 & 237 & 0 \\
\hline 9 & L6 & 47.3 & 1 & 237 & 0 \\
\hline 10 & L8 & 237 & 0 & 237 & 0 \\
\hline 11 & L5L6 & 146.5 & 1 & 237 & 0 \\
\hline 12 & L6L7 & 47.4 & 1 & 203.3 & 1 \\
\hline 13 & L6L8 & 47.4 & 1 & 237 & 0 \\
\hline 14 & L2L3L6 & 233.7 & 1 & 237 & 0 \\
\hline 15 & L2L5L6 & 128.1 & 1 & 237 & 0 \\
\hline 16 & G1G1L2 & 237 & 0 & 237 & 0 \\
\hline 17 & G1G1L3 & 237 & 0 & 237 & 0 \\
\hline 18 & G1G1L4 & 237 & 0 & 237 & 0 \\
\hline 19 & G1G1L2L5L6 & 237 & 0 & 237 & 0 \\
\hline 20 & G2G2L2 & 237 & 0 & 237 & 0 \\
\hline 21 & $\mathrm{G} 2 \mathrm{G} 2 \mathrm{~L} 3$ & 237 & 0 & 237 & 0 \\
\hline 22 & G2G2L4 & 237 & 0 & 237 & 0 \\
\hline 23 & G1G1G2G2 & 237 & 0 & 237 & 0 \\
\hline 24 & G1G1G2G2L2 & 100 & 1 & 237 & 0 \\
\hline 25 & G1G1G2G2L3 & 237 & 0 & 237 & 0 \\
\hline 26 & G1G1G2G2L4 & 237 & 0 & 237 & 0 \\
\hline \multirow[t]{2}{*}{27} & G1G1G2G2L5 & 130 & 1 & 191 & 1 \\
\hline & & & 8 states & & 2 States \\
\hline
\end{tabular}

Table 5. IEEE 9 Bus - Power Available to the Load for Contingencies with and without UPFC

\begin{tabular}{|c|c|c|c|c|c|}
\hline \multirow[t]{2}{*}{ S.No } & \multirow[t]{2}{*}{ Contingencies } & \multicolumn{2}{|c|}{ Without UPFC (MW) } & \multicolumn{2}{|c|}{ With UPFC (MW) } \\
\hline & & Power available to Load & $\mathrm{P}_{\mathrm{kj}}$ & Power available to Load & $\mathrm{P}_{\mathrm{kj}}$ \\
\hline 1 & No.of outages & 230 & 0 & 230 & 0 \\
\hline 2 & L3 & 229.1 & 1 & 230 & 0 \\
\hline 3 & L5 & 230 & 0 & 230 & 0 \\
\hline 4 & L2 & 227 & 1 & 230 & 0 \\
\hline 5 & L4 & 230 & 0 & 230 & 0 \\
\hline 6 & L6 & 230 & 0 & 230 & 0 \\
\hline 7 & L1 & 0.1 & 1 & 230 & 0 \\
\hline 8 & G2 & 110.4 & 1 & 110.4 & 1 \\
\hline 9 & G3 & 229.9 & 1 & 229.9 & 1 \\
\hline 10 & G1 & 230 & 0 & 230 & 0 \\
\hline 11 & G1 L3 & 229.1 & 1 & 230 & 0 \\
\hline 12 & G1 L5 & 230 & 0 & 230 & 0 \\
\hline 13 & G1 L2 & 227 & 1 & 227 & 1 \\
\hline 14 & G2 L3 & 134.8 & 1 & 134.8 & 1 \\
\hline 15 & G2 L5 & 147.3 & 1 & 147.3 & 1 \\
\hline 16 & G2 L2 & 2.3 & 1 & 40.5 & 1 \\
\hline 17 & G3 L3 & 149.5 & 1 & 202.2 & 1 \\
\hline 18 & G3 L5 & 230 & 0 & 230 & 0 \\
\hline 19 & G3 L2 & 223.6 & 1 & 230 & 0 \\
\hline 20 & G1 G2 L1 & 0.1 & 1 & 0.1 & 1 \\
\hline 21 & G2 L1 & 0.1 & 1 & 230 & 0 \\
\hline 22 & G2 G3 L1 & 0.3 & 1 & 102 & 1 \\
\hline 23 & G2 G3 L2 & 209.9 & 1 & 52.5 & 1 \\
\hline \multirow[t]{2}{*}{24} & L1 L3 & 0 & 1 & 0 & 1 \\
\hline & & & 17 states & & 11 states \\
\hline
\end{tabular}




\section{RESULTS}

Load point and system indices of RBTS are evaluated and tabulated in Table 6. Expected load curtailment (ELC) is reduced to $0.071 \mathrm{MW}$ due to UPFC incorporation from $192 \mathrm{MW}$, which indicates $99 \%$ improvement in the supply to the load. Number of Load Curtailments (NLC) inorder to balance the generation and demand are also reduced to 0.002 / Year. Reduction in the Excepted Duration of Load Curtailment (EDLC) indicate the improved unintarupperted power supply to the load. $0.01 \mathrm{~h}$ EDLC of RBTS and $168 \mathrm{~h}$ of EDLC of IEEE 9 Bus system indicated reliability improvement of the respective systems. 99\% improvement is achieved in Bulk Power Interruption Index (BPII). Nearly $1795 \mathrm{MWh}$ energy not supplied to the load due to the contingencies. For the same contingencies due to UPFC incorporation almost same energy made available to the load, contribute for more reliable system and additional revenue generation for the transmission system.

Improved reliability indices of IEEE 9 Bus system are tabulated in Table 7. Reduction in ELC from $1339 \mathrm{MW}$ to $199 \mathrm{MW}$ indicate $85 \%$ improvement in the system performance. Supply interruption reduced to $2 \mathrm{~h}$ from $1127 \mathrm{~h}$ indicates highly reliable system. Improvement in Expected Energy Not Supplied (EENS) is $37 \%$. For RBTS 7.573 MWh/MW-yr to $0.00144 \mathrm{MWh} / \mathrm{MW}-\mathrm{yr}$ and for IEEE 9 Bus system $38 \mathrm{MWh} / \mathrm{MW}-\mathrm{yr}$ to $24 \mathrm{MWh} / \mathrm{MW}$-yr severity index (SI) reduction inducate reduction in bulk power energy curtailment.

Rs. 8,34,05,858/kW/Month or \$ 1176221.37 revenue is generated for IEEE 9 bus system and Rs. $1,40,11,592 / \mathrm{kW} /$ Month or $\$ 197596.84$ revenue is obtained for RBTS system with UPFC incorporation, ( 1 Rupee = USD 70.86). Inverstment to procure IGBT based converters, control circuitry, switchgear and installation of complete valve house costs around Rs. 150Cr. Payback period for RBTS and IEEE 9 Bus system are tabulated in Table 8. Payback period $=$ (investment / Revenue generated). For RBTS system and IEEE 9 Bus system payback period is Nine years and one and half years respectively.

Table 6. Load Point and System Indices of RBTS

\begin{tabular}{ccc}
\hline RBTS & Without UPFC & With UPFC \\
\hline Load Point Indices & & \\
ELC(MW) & 191.6847633 & 0.07141128 \\
NLC & 1.011650243 & 0.00211876 \\
EENS(MWh) & 1794.956267 & 0.34277062 \\
EDLC(h) & 9.46765074 & 0.01016984 \\
System Indices & & \\
BPII(MW/MW-yr) & 0.80879647 & 0.00030131 \\
SI(MWh/MW-yr) & 7.573655136 & 0.00144629 \\
\hline
\end{tabular}

Table 7. Load Point and System Indices of IEEE 9 bus System

\begin{tabular}{ccc}
\hline IEEE 9 Bus system & Without UPFC & With UPFC \\
\hline Load Point Indices & & \\
ELC(MW) & 1339.428248 & 198.8244 \\
NLC & 1126.878426 & 2.2884431 \\
EENS(MWh) & 24086.51943 & 15129.274 \\
EDLC(h) & 273.3631002 & 168.22509 \\
System Indices & & \\
BPII(MW/MW-yr) & 2.126076584 & 0.3155943 \\
SI( MWh/MW-yr) & 38.23257053 & 24.01472 \\
\hline
\end{tabular}

Table 8. Payback Period of RBTS and IEEE 9 Bus Systems

\begin{tabular}{|c|c|c|c|c|c|c|}
\hline System & $\begin{array}{l}\text { Power not } \\
\text { supplied to the } \\
\text { load due to } \\
\text { contingencies } \\
\text { without } \\
\text { UPFC(ELC } \\
\text { MW/Year) }\end{array}$ & $\begin{array}{l}\text { Power not } \\
\text { supplied to the } \\
\text { load due to } \\
\text { contingencies } \\
\text { with UPFC } \\
\text { (ELC } \\
\text { MW/Year) }\end{array}$ & $\begin{array}{l}\text { Improvement } \\
\text { in power } \\
\text { delivered } \\
\text { to the load due } \\
\text { to UPFC } \\
\text { Incorporation } \\
\text { (MW/Year) }\end{array}$ & $\begin{array}{c}\text { Transmission } \\
\text { tariff } \\
\text { (Rs/kW/Month) }\end{array}$ & $\begin{array}{c}\text { Revenue to } \\
\text { Tranmission } \\
\text { system } \\
\text { (Rs/kW/Month) }\end{array}$ & $\begin{array}{c}\text { Pay back } \\
\text { period (years) }\end{array}$ \\
\hline RBTS & 191.6847633 & 0.071411276 & 191.613352 & 73.1243 & 14011592.24 & 9 \\
\hline $\begin{array}{l}\text { IEEE } 9 \text { Bus } \\
\text { system }\end{array}$ & 1339.428248 & 198.8244021 & 1140.603846 & 73.1243 & 83405857.81 & $1 \frac{1 / 2}{2}$ \\
\hline
\end{tabular}

\section{CONCLUSIONS}

Novel contingency ranking with Markov model reliability evaluation is proposed. Markov model of IEEE 9 bus system is validated by binomial distribution method. Contingency ranking and selection criteria for RBTS and IEEE 9 Bus systems is clearly presented. Reliability improvement due to UPFC incorporation is assessed with PSSE simulation. Additional economic revenue to transmission system and payback period of UPFC is evaluated. Scheme to improve reliability is proposed in detailed manner and also economical profit associated with the proposed scheme is evaluated. 


\section{REFERENCES}

[1] Hamza Abunima, Jiashen Teh, Ching-Ming Lai and Hussein Jumma Jabir "A systematic review of Reliability Studies on Composite Power System: A Coherent Taxonomy, Motivations, Open challenges, Recommendations and New research Directions" Energies, MDPI Open Access Journal, vol. 11(9), pp. 1-37, September 2018.

[2] Jiashen Teh, Lai and Yu-Huei Cheng "Impact of the Real-Time Thermal Loading on the Bulk Electric System Reliability" IEEE Transactions on Reliability, Vol. 66, No 4, December 2017.

[3] Jiashen The and Ian Cotton "Reliability Impact of Dynamic Thermal Rating System in Wind Power Integrated Network" IEEE Transactions on Reliability, Vol.65, No 2, June 2016.

[4] Jiashen The "Uncertainty Analysis of Transmission Line End-of-life failure Model for Bulk Electric System Reliability Studies" IEEE Transactions on Reliability, Vol.67, No 3, September 2018.

[5] Jiashen Teh, Chia Ai Ooi, Yu-Huei Cheng, Muhammad Ammirrul Atiqi Mohd Zainuri and Ching-Ming Lai, "Composite Reliability Evaluation of Load Demand Side Management and Dynamic Thermal Rating Systems" www.mdpi.com/journal/energies

[6] Jiashen Teh, Ching-Ming Lai, Nor Asiah Muhamad, Chia Ai Ool, Yu-Huei Cheng, Muhammad Ammirrul Atiqi Mohd Zainuri and Mohamad Khairi Ishak "Prospects of Using the Dynamic Thermal Rating System for Reliable Electrical Networks: A Review" IEEE Access, Vol. 6, 2018.

[7] M.C. Ramachandran1, K. Elango2 "Improvement of power quality of power system using contingency analysis" International Journal of Engineering \& Technology, 7 (2.21) (2018) 237-241.

[8] Toshi Mandloi1, Anil K Jain2 "A study of power system security and contingency analysis" International Journal of Scientific Research Engineering \& Technology (IJSRET), ISSN 2278-0882 Volume 3, Issue 4, July 2014.

[9] Ali Absulwahhab and Abdulrazzaq "Contingency ranking of power systems using a performance index" Internation Research Journal of Engineering and Technology (IRJET), e-ISSN 2395-0056, Volume: 02 Issue02, may 2015.

[10] Venkata Satheesh Babu K, Madhusudan V and Ganesh V. "Probabilistic Perfomance Index based Contingency Screening for Composite Power system Reliability Evaluation" International Journal of Electrical and Computer Engineering (IJECE), pp. 2661-2670, ISSN: 2088-8708, Vol. 8, No. 5, October 2018.

[11] E.Sreeshobha and P.V.N.Prasad "Implementation of Load flow based Reliability Indices evaluation Method and Comparison with Constant Capacity based Reliability Indices Evaluation for Three bus Transmission System" International conference on Electrical Electronics Computers Communication, Mechanical and Computing EECCMC-2018.

[12] Raheema Syed, P.Srinivas Varma, R.B.R.Rrakash, Ch.Rami Reddy "Unit commitment based reliability analysis with contingency constraint" Indonesian Journal of Electrical Engineering and Computer Science (IJEECS), vol 16, No.1, October 2019, pp. 74-81, ISSN:2502-4752.

[13] Narain G.Hingorani, Lazlo Gyugi, “Understanding FACTS”, IEEE Press, New York 1999.

[14] Alok Kumar Mohanty, Amar Kumar Barik "Power System Stability Improvement Using FACTS Devices" International Journal of Modern Engineering Research (IJMER), Vol.1, Issue.2, pp. 666-672 ISSN: 2249-6645.

[15] Rakeshkumar B.Shah "Comparative Study of FACTS Devices and Different Types of FACTS Controller" PARIPEX- Indian Journal of Research, Vol. 8(1), January 2019 ISSN2250-1991.

[16] I.A.Ethmane, A.K.Mahmoud, M.Maaroufi and A.Yahfdhou "Transient stability enhancement of statcom integration in power grid" Indonesian Journal of Electrical Engineering and Computer Science (IJEECS), vol 16, No.2, November 2019, pp. 553-561, ISSN:2502-4752.

[17] Timothy J.E.Miller "Reactive Power Control in Electric Systems" Wiley 2014ISBN:978-81-265-2520-1.

[18] Raja Masood Larik, Mohd.Wazir Mustafa, Manoj Kumar Panjwani "A statistical jacobian application for power system optimization of voltage stability" Indonesian Journal of Electrical Engineering and Computer Science (IJEECS), vol 13, No.1, January 2019, pp. 331-338, ISSN:2502-4752.

[19] Yong Hua Song and Allan T Johns "Flexible AC Transmission Systems(FACTS)" Shankar's Book Agency Pvt.Ltd. 2009, ISBN:978-81-908588-0-9.

[20] Vaibha Kolhe, Kunal Kolhe, Shrutika Choudhari and Susmita Khedekar .. 1..2 "A case Study: Energy Conservation through Energy Audit at Kandalgaon substation" International Conference on Energy, Communication, Data Analytics and Soft Computing ICECDS-2017.

[21] PSS/E "Power system simulation for engineers software".

[22] Deepinder Kaur Mander and GS Virdi "Result Analysis on Load Flow by Using Newton Raphson Method" International Journal of Advanced Research in Electrical, Electronics and Instrumentation Engineering (An ISO), 3297: 2007 Certified Organization Vol. 6, Issue 7, July 2017.

[23] Roy Billinton and Ronald N.Allan "Reliability evaluation of power systems" Springer International Edition 1996.

[24] Transmission Planning Criteria Manual- central Electricity Authority 2013.

[25] Roy Billinton "Reliability Evaluation of Engineering system", Second edition, Springer International Edition 2007.

[26] “Telangana State Electricity Regulatory Commission 2019”, India. 


\section{BIOGRAPHIES OF AUTHORS}
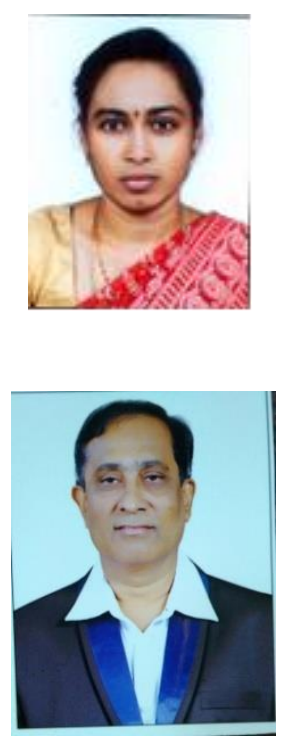

E.Sreeshobha graduated in Electrical \& Electronics Engineering from Jawaharlal Nehru Technological University in 2001, and received M.Tech in Power Electronics in 2007 from JNTU College of Engineering, Hyderabad and pursing Ph.D from Osmania University, Hyderabad. She has more than 12 years of teaching and 3 years of industrial experience and presently working as Assistant Professor in the Department of Electrical Engineering, University College of Engineering, Osmania University, Hyderabad, India. She presented many research papers in various national and international journals and conferences. Her research interests include Power Electronics, Power Electronics Applications into Power Systems and Drives. She presented technical papers in Hongkong in 2013.

Dr.P.V.N.Prasad graduated in Electrical \& Electronics Engineering from Jawaharlal Nehru Technological University, Hyderabad in 1983 and received M.E in Industrial Drives \& Control from Osmania University, Hyderabad in 1986. Presently he is serving as Professor in the Department of Electrical Engineering, Osmania University. He received his Ph.D in Electrical Engineering from Osmania University in 2002 His areas of interest are Simulation of Electrical Machines \& Power Electronic Drives and Reliability Engineering. He is a Fellow of Institution of Engineers India and member of Indian Society for Technical Education. He is recipient of Dr.Rajendra Prasad Memorial Prize, Institution of Engineers (India) in 1994 for best paper. He has got about 120 publications in National and International Journals, Conferences \& Symposia and presented technical papers in Thailand, Italy, U.S.A. and Singapore 